\title{
Stimulant Reduction Intervention using Dosed Exercise (STRIDE) - CTN 0037: Study protocol for a randomized controlled trial
}

\author{
Madhukar H Trivedi ${ }^{*}$, Tracy L Greer ${ }^{1}$, Bruce D Grannemann ${ }^{1}$, Timothy S Church², Eugene Somoza ${ }^{3}$, \\ Steven N Blair ${ }^{4,5}$, Jose Szapocznik ${ }^{6}$, Mark Stoutenberg ${ }^{6}$, Chad Rethorst ${ }^{1}$, Diane Warden ${ }^{1}$, Kolette M Ring $^{1}$, \\ Robrina Walker ${ }^{1}$, David W Morris ${ }^{1}$, Andrzej S Kosinski ${ }^{7}$, Tiffany Kyle ${ }^{8}$, Bess Marcus ${ }^{9}$, Becca Crowell $^{10}$, Neal Oden ${ }^{11}$ \\ and Edward Nunes ${ }^{12}$
}

\begin{abstract}
Background: There is a need for novel approaches to the treatment of stimulant abuse and dependence. Clinical data examining the use of exercise as a treatment for the abuse of nicotine, alcohol, and other substances suggest that exercise may be a beneficial treatment for stimulant abuse, with direct effects on decreased use and craving. In addition, exercise has the potential to improve other health domains that may be adversely affected by stimulant use or its treatment, such as sleep disturbance, cognitive function, mood, weight gain, quality of life, and anhedonia, since it has been shown to improve many of these domains in a number of other clinical disorders. Furthermore, neurobiological evidence provides plausible mechanisms by which exercise could positively affect treatment outcomes. The current manuscript presents the rationale, design considerations, and study design of the National Institute on Drug Abuse (NIDA) Clinical Trials Network (CTN) CTN-0037 Stimulant Reduction Intervention using Dosed Exercise (STRIDE) study.

Methods/Design: STRIDE is a multisite randomized clinical trial that compares exercise to health education as potential treatments for stimulant abuse or dependence. This study will evaluate individuals diagnosed with stimulant abuse or dependence who are receiving treatment in a residential setting. Three hundred and thirty eligible and interested participants who provide informed consent will be randomized to one of two treatment arms: Vigorous Intensity High Dose Exercise Augmentation (DEI) or Health Education Intervention Augmentation (HEI). Both groups will receive TAU (i.e., usual care). The treatment arms are structured such that the quantity of visits is similar to allow for equivalent contact between groups. In both arms, participants will begin with supervised sessions 3 times per week during the 12-week acute phase of the study. Supervised sessions will be conducted as one-on-one (i.e., individual) sessions, although other participants may be exercising at the same time. Following the 12-week acute phase, participants will begin a 6-month continuation phase during which time they will attend one weekly supervised DEI or HEI session.
\end{abstract}

Clinical Trials Registry: ClinicalTrials.gov, NCT01141608

http://clinicaltrials.gov/ct2/show/NCT01141608?term=Stimulant+Reduction+Intervention+using+Dosed + Exercise\&rank=1

Keywords: stimulant abuse, stimulant dependence, exercise, health education, behavioral intervention

\footnotetext{
* Correspondence: madhukar.trivedi@utsouthwestern.edu

'The University of Texas Southwestern Medical Center at Dallas, 5323 Harry

Hines Blvd., Dallas, Texas, 75390-9119, USA

Full list of author information is available at the end of the article
} 


\section{Background}

There is a need for novel approaches to the treatment of stimulant use disorders. Stimulant use disorders are chronic, relapsing illnesses with few highly efficacious treatments [1]. In control conditions (Treatment as Usual; TAU) for substance use disorders, typically only about $13 \%$ of participants achieve abstinence [1]. Abstinence rates for treatments designed to augment TAU vary widely - ranging from 14-60\%[2-5] - depending on the outcome variable and primary endpoint selected. Currently, the best treatments for cocaine and other stimulant use disorders are behavioral treatments that combine cognitive behavioral therapy (CBT) with contingency management $[1,6]$. However, it is clear that new treatments are still needed for stimulant abuse and dependence.

Exercise is a promising new treatment option for stimulant abuse and dependence. Randomized controlled trials examining exercise to improve outcomes in smoking cessation provide some of the most convincing support for investigating the use of exercise (and most frequently, vigorous intensity exercise) to improve outcomes in stimulant abuse [7-11]. While randomized controlled trials in patients abusing substances other than tobacco or alcohol are not yet available, some studies report benefits such as increased abstinence and reduced substance use that are associated with the use of exercise [12-14]. Furthermore, in a post hoc analysis of data from 187 participants in two randomized trials evaluating contingency management for the treatment of substance abuse disorders $[15,16]$, participants who reported engaging in exercise-related activities had an increased length of abstinence [17]. In a recent pilot study of moderate-intensity aerobic exercise added to treatment for 16 individuals with substance dependence, percent days abstinent significantly increased from baseline, and $66.7 \%$ of the sample had been continuously abstinent at the end of a 12-week intervention [18].

Exercise may also provide additional health benefits and functional improvements for stimulant users. Exercise has been shown to reduce depression and anxiety during alcohol treatment [19-21], as well as smoking cessation treatment [22-24]. Exercise is also associated with improved quality of life [25] and sleep [26], both of which are disrupted by stimulant use even after abstinence is achieved $[27,28]$. In addition, concern about weight gain following cessation of abused substances may increase risk of substance use relapse [29-31], and regular exercise may prevent or reduce post cessation weight gain. Furthermore, Greenwood et al. [32] has demonstrated improvements in hippocampal-dependent contextual learning and memory in rats with exercise. Similar results have been found for exercise-induced hippocampal neurogenesis and improvements in spatial memory in rats and mice [33-35]. Since substance abuse has been associated with memory impairments that are influenced by hippocampal function [36], exercise may be associated with improved memory for these individuals.

Exercise may improve outcomes through any of several possible mechanisms. Exercise is likely to impact the underlying biology of addicted persons, as well as act as a behavioral treatment intervention. Summarizing studies of the effect of exercise on neurotransmitters [37] conclude that exercise results in changes in synthesis and metabolism within central dopaminergic, noradrenergic, and serotonergic systems, all of which are implicated in addiction. Additional biological effects of exercise may include decreased reactivity to stress [38] and decreased use of substances as a way of coping with stress [39]. Exercise-induced improvements in self-efficacy $[40,41]$ may be another mechanism for improving outcomes. It has also been suggested that exercise may be a distraction [42], allowing attention to be diverted from urges to use substances [43] or a positive lifestyle change that can substitute for use of substances $[44,45]$.

The current paper provides a description of the design of the Stimulant Reduction Intervention using Dosed Exercise (STRIDE) study, a multisite randomized, controlled trial aimed at comparing the augmentation of treatment as usual with either an exercise or health education intervention in a stimulant abusing population. If exercise is found to improve outcomes for substance use disorders, the public health significance would be substantial. A novel, low cost treatment would be available for substance users that could assist with both acute treatment and reducing long-term relapse.

There were several challenges in the design of such a trial, such as: 1) determining the appropriate comparison group, 2) selecting the appropriate primary outcome, and 3) selecting the appropriate setting for the conduct of the study. These challenges were enhanced by the fact that there are no standardized designs that have focused on how best to assess the effects of augmentation treatments, particularly those that take into account patients' transition from residential to intensive outpatient and longer term treatment. This problem is compounded by the fact that there is no agreed upon single outcome to best assess the effectiveness of a treatment for stimulant abuse [46]. This manuscript provides a general description of the STRIDE trial and how the particular issues associated with this type of study were addressed.

\section{Methods/Design}

\section{Overview}

STRIDE is designed to test the efficacy of exercise or health education augmentation for the treatment of stimulant abuse. This study will evaluate individuals diagnosed with stimulant abuse or dependence (cocaine, 
methamphetamine, amphetamine or other stimulant, except caffeine or nicotine, as defined by the Diagnostic and Statistical Manual of Mental Disorders, Fourth Edition, Text Revision [DSM-IV-TR]) who are receiving treatment in a residential setting. Three hundred and thirty eligible and interested participants who provide informed consent will be randomized to one of two treatment arms: Vigorous Intensity High Dose Exercise Augmentation (DEI) or Health Education Intervention Augmentation (HEI). Both groups will receive TAU (i.e., usual care). The study intervention begins while participants are receiving treatment in a program with a residential stay. The treatment arms are structured such that the quantity of visits is similar to allow for equivalent contact between groups. In both arms, participants will begin with supervised sessions 3 times per week during the 12-week acute phase of the study. Supervised sessions will be conducted as one-on-one (i.e., individual) sessions, although other participants may be exercising at the same time. Following the 12 -week acute phase, participants will begin a 6-month continuation phase during which time they will attend one weekly supervised DEI or HEI session. The study design is displayed in Figure 1. A Data and Safety Monitoring Board assembled by NIDA approved the final study design and will be providing ongoing monitoring throughout implementation of the trial.

\section{Study Sites}

This study is being conducted on the National Drug Abuse Treatment Clinical Trials Network (CTN). Participating sites are CTN Community Treatment Programs (CTPs) meeting site characteristics identified based on the requirements of the study protocol [47]. Each site is partnered with a Regional Research and Training Center (RRTC), an academic institution led by a substance use researcher. The RRTC helps guide the conduct of the study at the site. The site characteristics include: 1) a treatment program with a residential component and length of stay generally between 21 and 30 days; 2) no formal exercise program that includes more than an hour a week of exercise, or willingness to exclude participants from the program; 3) availability of community outpatient treatment at or near the residential setting where the study is located so that it is feasible for participants to return to the study site to complete study activities for the full 9 months of the study; 4) a sufficient number of clients admitted to residential treatment per month who might be eligible to participate in the study; and 5) adequate space to accommodate study staff and activities. Sites were selected in two groups based on survey responses, phone interviews, and site visits. Four Wave 1 sites were identified and approved to begin the study about 6 months earlier than the five Wave 2 sites. This model allows for early identification and resolution of any operational issues in the conduct of the study.

\section{Aims}

The primary aim of STRIDE is to compare percent days of abstinence between the DEI and HEI groups based on stimulant use during the 12 -week acute phase. It is hypothesized that DEI will be associated with significantly greater $(p<0.05)$ percent days of abstinence than HEI as measured by a corrected Timeline Followback. Timeline Followback (TLFB) $[48,49]$ is collected as described by Sobell and with the aid of a Substance Use Diary. Additionally, a urine drug screen is collected three times per week to improve the accuracy of and correct the self-report data from the TLFB at the time of data analysis based on an algorithm [50].

Secondary aims of STRIDE are: 1) to compare time to relapse (defined as second positive urine test [for stimulants] and use of drugs (assessed via TLFB) between the DEI and HEI groups; 2) to evaluate withdrawal symptoms between the DEI and HEI groups; 3) to evaluate drug use and related outcomes for other substances (categorized as alcohol, cannabinoids, nicotine, opioids, or sedative/ hypnotic/anxiolytics); 4) to compare time to dropout from substance abuse treatment between the DEI and HEI groups; 5) to evaluate drug use and related outcomes during the entire course of the study (i.e., randomization to 9 months). Finally, as an exploratory aim, we will attempt to determine if there are additional health benefits to using exercise augmentation in the treatment of substance use disorders. Specifically, we will examine the effects of exercise augmentation on sleep, cognitive function, mood, quality of life, anhedonia, and weight gain compared to HEI over the course of the 12-week acute phase and over the 9-month study period.

\section{Eligibility Criteria}

Participants will be ambulatory males or females, ages 18 to 65 , who have been admitted to substance use treatment in a participating residential setting. Participants must have self-reported stimulant drug use (cocaine, methamphetamine, amphetamine, or other stimulant, excluding caffeine and nicotine) within the 30 days prior to admission for residential treatment and meet DSMIV-TR criteria for substance abuse or dependence for stimulants within the last 12 months. They must receive medical clearance through a protocol-defined maximal exercise test (in accordance with American College of Sports Medicine (ACSM) guidelines [51]) and a careful history and physical examination from protocol-approved medical personnel. Participants must have the ability to understand and willingness to provide written informed consent. Persons meeting the following criteria will be excluded from participation: general medical condition(s) 


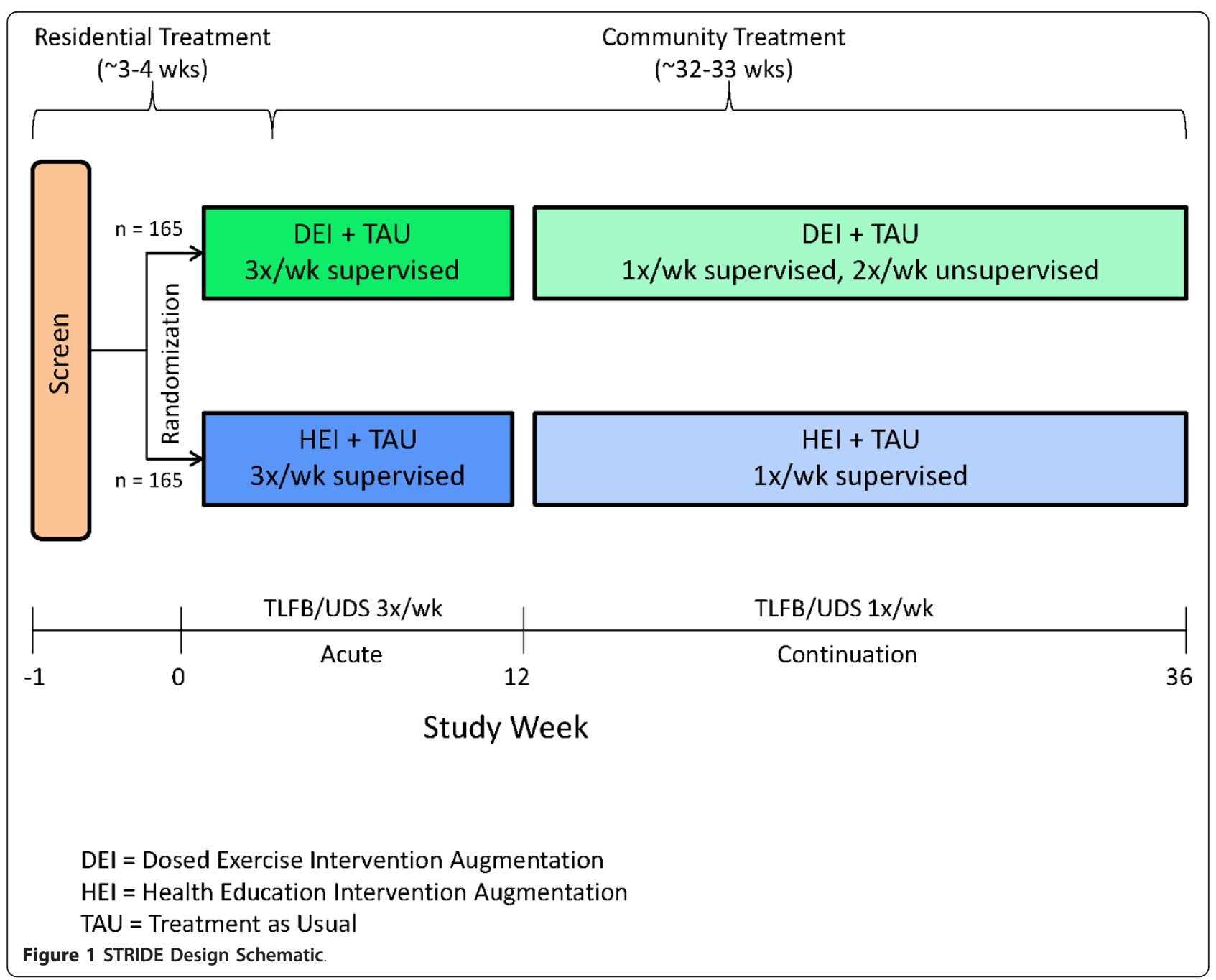

that contraindicate exercise, opiate dependence, psychosis, or other psychiatric issue(s) that poses a safety risk, pregnancy, or concomitant treatment with beta blockers or opioid replacement therapy (e.g., methadone or bupenorphine).

\section{Exercise Intervention}

\section{Intervention Overview}

Participants in DEI will perform their exercise sessions on a Life Fitness 95T-seriesTreadmill (Schiller Park, IL). Prescribed exercise doses and intensities will be ramped over the initial 3 weeks of the study to allow for a gradual familiarization to the study protocol and the accompanying physical demands (see Table 1). Exercise intensity will be based on a percentage of the maximum heart rate (HR) achieved during the baseline maximal exercise test. The 12 kilocalories"kilogram of bodyweight ${ }^{-1}{ }^{*}$ week $^{-1}$ (KKW) weekly exercise dose was chosen to approximate public health dose guidelines http://www.health.gov/ paguidelines (i.e., approximately 30-50 min, 3-5 days per week). Participants will be scheduled to complete their weekly exercise dose over three exercise sessions. However, additional exercise sessions can be scheduled for those needing more than three sessions per week to achieve their target dose.

\section{Exercise Sessions}

During the supervised exercise sessions, participants will perform an active warm-up for 5 minutes prior to initiation of the exercise prescription. Polar RS 400 HR monitors (Kempele, Finland) will be used to continuously monitor participants' heart rate (HR) throughout the

Table 1 Ramping Schedule for Exercise Dose and Intensity

\begin{tabular}{ccc}
\hline Week No. & $\begin{array}{c}\text { Exercise Dose } \\
(\text { KKW })\end{array}$ & $\begin{array}{c}\text { Exercise Intensity } \\
\left(\% \text { HR }_{\text {max }}\right)\end{array}$ \\
\hline 1 & 6 & $50-60$ \\
2 & 9 & $60-70$ \\
$3-36$ & 12 & $70-85$ \\
\hline
\end{tabular}


exercise session to ensure that they are within their target $\mathrm{HR}$ zone (i.e., $70-85 \%$ of an individual's $\mathrm{HR}_{\max }$ ). Typically, participants can achieve a HR of $70-85 \%$ by either walking briskly at an incline or by running at zero incline. The speed and/or grade of the treadmill will be continually adjusted to maintain participant HR within the target HR zone while allowing the participants some flexibility in customizing their exercise session. A global Rating of Perceived Exertion (RPE), assessed using Borg's RPE scale, will be taken at the conclusion of each exercise session. At the completion of the exercise session, participants will perform an active cool down (0 grade and $50-70 \%$ of speed) until their HR returns to within $15 \%$ of their resting value. Participants will then be led through a 5-10 minute stretching routine.

During the continuation phase, participants will complete one supervised exercise session per week at the CTP exercise facility with the remainder of their exercise dose to be completed in unsupervised exercise sessions. Exercise Facilitators will aid the participant in identifying a safe location for completing their unsupervised sessions, scheduling these sessions, and planning other practical concerns related to engaging in exercise during the continuation phase. Participants will also receive assistance in developing measured exercise courses to allow for estimates of time and distance covered at each unsupervised session. Participants will record a global RPE score at the end of each unsupervised exercise session.

\section{Exercise Safety}

Those who are not safe to exercise, including those with greater than Stage 1 hypertension will not be randomized. Prior to each exercise session, participants will sit undisturbed for 5 minutes before assessment of their resting heart rate and blood pressure (BP). If a participant's resting $H R$ is $\geq 100$, it will be re-measured after an additional 5-minute rest period. If a participant's resting HR remains $\geq 100$, the exercise session will be rescheduled for another day. Likewise, if a participant's resting $\mathrm{BP}$ is $\geq 160 / 100$, it will be re-measured after an additional 5 -minute rest period. If a participant's resting BP remains $\geq 160 / 100$, the exercise session will be rescheduled for another day. During the session, BP will be assessed after 5 minutes to monitor for adverse responses to the onset of the exercise. BP will continue to be monitored if an exaggerated acute response is observed (i.e., SBP $>200$ $\mathrm{mmHg}$ ). The exercise session will be halted if an extreme $\mathrm{BP}$ response $(\mathrm{SBP}>250 \mathrm{mmHg}$ or remains unchanged despite an increase in workload, or DBP increase > $15 \mathrm{mmHg}$ ) is observed. Following the cool down, a final $\mathrm{BP}$ will be taken before the participant is cleared to leave the facility. Guidelines are also present for referral to appropriate medical care and additional physician clearance based on blood pressure readings.

\section{Health Education Intervention}

The health education intervention is structured to provide equivalent contact time to that of the exercise intervention. During the acute phase, participants will complete three supervised sessions per week. Visits will be weekly during the continuation phase. During HEI sessions participants will view educational items such as didactic presentations, readings, Web sites, and audio or video materials. Instructional topics include areas such as healthy eating, preventive health care and recommended health screenings, accessing health care resources, and other health-related topics that are relevant to adults with substance use disorders. Exercise and topics central to substance use treatment (e.g., coping with cravings, relapse prevention) are not included to prevent intervention contamination and not change TAU, respectively. Participants will be encouraged to suggest topics of interest to help maintain their involvement and engagement in the sessions throughout the duration of the study. The HEI program is modeled after similar programs that have been used successfully as control groups in clinical trials examining exercise as an intervention $[7,52,53]$.

\section{Behavioral Adherence Program}

A comprehensive behavioral adherence approach to facilitating and monitoring fidelity to exercise dose has been developed by our team through our work in conducting exercise interventions in depressed populations [54]. Individuals in both treatment arms will receive adherence support through the behavioral adherence program. This program serves to: 1) provide necessary tools and support for participants to help them successfully complete the intervention and 2) allow for individualized monitoring to address person-specific adherence issues and barriers to the assigned intervention. The program includes: 1) multidisciplinary psychoeducation about adherence, 2) intervention skills training, 3) weekly intervention prescription provided via the study Web site, 4) self-monitoring of intervention adherence and performance, 5) adherence feedback from study Web site and intervention facilitator, and 6) weekly intervention planning (individually-tailored plan). Facilitators assist participants each week throughout the study with planning and adhering to a schedule for completion of their intervention sessions. Facilitators proactively review both potential and identified barriers to adherence (e.g., transportation, work schedules) and discuss possible solutions to work around these barriers (e.g., planning bus routes, providing flexible appointment times). Participants work with facilitators to use the study Web site during supervised 
sessions and are able to continue using the Web site during home-based sessions if they have access to the Internet.

\section{Study Assessments}

Table 2 summarizes the assessments used throughout the study, their main purpose, their frequency of administration, and psychometric properties if available.

\section{Diagnostic and Screening Assessments}

At screening, standard demographic information will be collected from all participants (e.g., gender, race, ethnicity, etc.). Contact information will be obtained and updated monthly and additionally as needed. DSM-IV-TR alcohol and substance abuse and dependence will be assessed with the substance use modules of the World Health Organization (WHO) Composite International Diagnostic Interview (CIDI) (Version 2.1)[55,56]. Additional DSM-IV Axis I diagnostic information will be obtained using the MINI International Neuropsychiatric Interview (MINI)[57].

\section{Medical Evaluation}

Medical history will be obtained using a self-report medical history form designed to collect information about history and/or treatment of medical conditions, such as heart disease, high blood pressure, diabetes, and cancer. The form also assesses allergies, past surgeries, tobacco and alcohol use, family history of medical conditions, medical symptoms over the past 30 days, and prior and concomitant medications. Additionally, participants will complete the Self-Administered Comorbidity Questionnaire (SCQ) [58] and the Physical Activity Readiness Questionnaire (PAR-Q)[59]. Medical personnel will conduct a medical history and physical exam, and laboratory tests (chemistry, hematology, lipid profile, and urinalysis) will be obtained as part of the medical screening process.

Maximal exercise testing will be conducted during the screening process to examine cardiorespiratory responses in order to rule out ischemic response to exercise (with its implications of cardiovascular disease), to identify participants for whom exercise might be hazardous, and to provide data for the exercise prescription. The test will be repeated at the end of the 12-week acute phase (or during an early termination visit). A trained technician will process the test data and a report will be generated that contains the following information: 1) participant's symptoms before, during, and after testing; 2) maximal heart rate achieved and percent of predicted maximal heart rate achieved; 3) time on treadmill and estimated maximal metabolic equivalent (METS) achieved; and 4) ECG interpretation. A designated medical staff member will be responsible for reviewing the participant's medical history and evaluating results from the medical exam, maximal testing, and lab results to determine whether or not the participant is medically cleared to exercise.
Eligible participants complete a comprehensive baseline assessment. Since there are numerous baseline assessments, these may be distributed over more than one day if necessary. The frequency and type of ongoing assessments are equivalent in both groups, with the exception of blood pressure and heart rate obtained for exercise participants prior to every supervised exercise session. Descriptions of ongoing study assessments are described by category below (as well as in Table 2).

\section{Substance Use and Treatment Assessments}

The Timeline Followback [48,49] and Substance Use Diary (SUD) will be used to acquire information on alcohol and drug use, including cocaine and other stimulants. The TLFB is a semi-structured interview that uses a calendar to prompt participants to provide retrospective estimates of their daily drug use over a specified period of time that can vary up to 12 months before the interview date. The measure provides prompts to facilitate accurate recollection of use behavior. The SUD, a pocket calendar given to participants at the beginning of the study to prospectively record substance use, will assist with accurate recall when completing the TLFB at each study visit.

Qualitative urine drug screens (UDS) will be conducted at baseline, three times a week in the first 12 weeks, and once a week in the subsequent 6 months. The screen will test for the following substances: marijuana, cocaine, opiates, amphetamine, methamphetamine, benzodiazepines, barbiturates, methadone, methylenedioxymethamphetamine (MDMA, Ecstasy), and oxycodone. UDSs will also be used to corroborate information on the TLFB.

The Addiction Severity Index-Lite (ASI-Lite) will be administered by research staff to examine multiple domains that are commonly affected by substance use, including medical, employment/self-support, alcohol/drug use, legal status, family/social, and psychiatric status [60]. Stimulant craving (cocaine, methamphetamine, and other stimulants) will be assessed using the Stimulant Craving Questionnaire-Brief (STCQ-Brief; adapted from Sussner et al. [61] and derived from the 10-item Cocaine Craving Questionnaire-Brief and the original 46-item Cocaine Craving Questionnaire-Now [62]). Signs and symptoms of stimulant (cocaine, methamphetamine, and other stimulants) abstinence will be evaluated using the Stimulant Selective Severity Assessment (SSSA; adapted from Kampman et al. [63]). Baseline nicotine dependence will be evaluated using the Fagerstrom Test for Nicotine Dependence (FTND) $[64,65]$ and number of cigarettes smoked per day will be captured on the TLFB.

\section{Mood and Functional Measures}

Symptoms of depression will be measured by the Quick Inventory of Depressive Symptomatology - Clinician Rated version (16-item)[66-70], and the Snaith-Hamilton 
Table 2 STRIDE Assessments

\begin{tabular}{|c|c|c|}
\hline Assessment & Frequency & Purpose and Psychometrics \\
\hline \multicolumn{3}{|c|}{ Diagnostic and Screening Measures } \\
\hline Demographics Form & Screen & To gather basic demographic information. \\
\hline $\begin{array}{l}\text { Composite International Diagnostic } \\
\text { Interview (CIDI) (Modules A, J, \& L) }\end{array}$ & Screen & $\begin{array}{l}\text { To obtain substance use diagnoses. Tests of the reliability of the } \\
\text { CIDI-SAM based on DSM-IV diagnoses for cocaine dependence } \\
\text { compared to SCID interviews done by trained clinicians, had } \\
\text { percent agreement of } 82.6 \% \text {, with kappa }=0.61 \text {. With specific } \\
\text { criteria for the diagnosis, kappas ranged between } 0.68 \text { and } 0.55 \text {. }\end{array}$ \\
\hline $\begin{array}{c}\text { Mini International Neuropsychiatric } \\
\text { Interview (MINI) }\end{array}$ & Screen & $\begin{array}{c}\text { To identify Axis I psychiatric diagnoses (excluding substance use } \\
\text { disorders). In comparison to the Structured Clinical Interview for } \\
\text { DSM-IV Disorders (SCID-P), kappa values were good (only one } \\
\text { diagnosis }<.50 \text { ), specificities and negative predictive values were } \\
.85 \text { or higher across diagnoses, and in general, sensitivity was .70 } \\
\text { or higher [113]. }\end{array}$ \\
\hline Locator Form & Screen, monthly & To obtain contact information for each participant. \\
\hline Prior and Concomitant Medications & Screen, weekly & To assess prescribed medications taken by the participant. \\
\hline $\begin{array}{l}\text { Self-Administered Comorbidity } \\
\text { Questionnaire (SCQ) }\end{array}$ & Screen & $\begin{array}{c}\text { To assess the presence of medical problems, their severity, and } \\
\text { whether or not the condition limits functioning. An intraclass } \\
\text { correlation coefficient of } 0.94 \text { shows good test-retest reliability and } \\
\text { is comparable to the Charlson Index intraclass correlation } \\
\text { coefficient of } 0.92 \text {. }\end{array}$ \\
\hline
\end{tabular}

\begin{tabular}{ccc}
\hline $\begin{array}{c}\text { Physical Activity Readiness } \\
\text { Questionnaire-Revised (PAR-Q) }\end{array}$ & Screen & $\begin{array}{c}\text { To determine whether a person needs to consult with their } \\
\text { physician prior to engaging in an exercise program. }\end{array}$ \\
\hline Medical History- Self-report Form & Screen & $\begin{array}{c}\text { To obtain information that will facilitate the conduct of the } \\
\text { physical exam, clinician-rated medical history, and maximal } \\
\text { exercise test. }\end{array}$ \\
\hline $\begin{array}{c}\text { Maximal Exercise Test Screening } \\
\text { Questions }\end{array}$ & Screen & $\begin{array}{c}\text { To aid the medical personnel in ensuring that it is safe for the } \\
\text { participant to undergo the maximal exercise test }\end{array}$ \\
\hline
\end{tabular}

Maximal Exercise Testing Screen, week 13

To examine cardiorespiratory responses in order to rule out ischemic response to exercise, to identify participants for whom exercise might be hazardous, and to provide data for the exercise prescription.

\begin{tabular}{cll}
\hline Physical Exam/Medical History & Screen & To provide clearance for exercise. \\
\hline Laboratory Tests & Screen & To provide clearance for exercise. \\
\hline & Substance Use and Treatment Assessments & \\
\hline
\end{tabular}

Timeline Followback (TLFB)* Screen, $3 X / w k$ for $1^{\text {st }} 3$ months, $1 \mathrm{X} / \mathrm{wk}$ for $\quad$ To quantify days of substance use for calculation of primary

*Primary outcome measure next 6 months outcome (percent days abstinent). The TLFB has been shown to have high test-retest reliability (ICC values ranging from 0.70 to .94, with all $p<0.001$ ), good convergent and discriminate validity, and acceptable agreement between the TLFB and urine drug screens (Yule's Y of 87 or greater for amphetamines and cocaine) [114].

\begin{tabular}{|c|c|c|}
\hline Urine Drug Screen (UDS) & $\begin{array}{l}\text { Baseline, } 3 X / w k \text { for } 1^{\text {st }} 3 \text { months, } 1 X / w k \\
\text { for next } 6 \text { months }\end{array}$ & To test for substance use and to inform TLFB. \\
\hline $\begin{array}{c}\text { Stimulant Craving Questionnaire- } \\
\text { Brief (STCQ-Brief) }\end{array}$ & Baseline, weekly & $\begin{array}{l}\text { To assess current craving for stimulants. The CCQ-Brief, from which } \\
\text { the STCQ-Brief is adapted, has high internal consistency, with } \\
\text { Cronbach's alpha ranging from } 0.87 \text { [115] to } 0.90 \text { [61]. The } \\
\text { instrument also has good construct validity and has shown to } \\
\text { correlate well with other craving measures [115]. }\end{array}$ \\
\hline $\begin{array}{l}\text { Stimulant Selective Severity } \\
\text { Assessment (SSSA) }\end{array}$ & Baseline, weekly & $\begin{array}{l}\text { To assess signs and symptoms of stimulant abstinence. The } \\
\text { Cocaine Selective Severity Assessment, from which the SSSA is } \\
\text { adapted, has been shown to have good inter-rater reliability } \\
\text { (correlation coefficient }=0.92, p<0.001 \text { ) and internal consistency } \\
\text { (Cronbach's alpha }=0.80 \text { ). }\end{array}$ \\
\hline $\begin{array}{l}\text { Addiction Severity Index-Lite (ASI- } \\
\text { Lite) }\end{array}$ & Baseline, weeks 13, 25, 37 & $\begin{array}{l}\text { To assess common problems associated with drug use. The CTN } \\
\text { version is similar to the ASI-Lite-Veterans Administration (ASI-L-VA) } \\
\text { and should have similar psychometric characteristics. Specifically, } \\
\text { intraclass correlations between the ASI fifth edition (ASI-5) and } \\
\text { ASSI-L-VA are } 0.79 \text { for alcohol, } 0.79 \text { for drug, } 0.85 \text { for legal, } 0.46 \text { for } \\
\text { family/social, and } 0.53 \text { for psychiatric [116]. }\end{array}$ \\
\hline
\end{tabular}


Table 2 STRIDE Assessments (Continued)

\begin{tabular}{|c|c|c|}
\hline $\begin{array}{l}\text { Fagerstrom Test for Nicotine } \\
\text { Dependence (FTND) }\end{array}$ & Baseline & $\begin{array}{l}\text { To assess dependence on nicotine. The FTND has shown } \\
\text { acceptable internal consistency (Cronbach's alpha of } 0.61 \text { ) and } \\
\text { correlates significantly with other measures of smoking } \\
\text { consumption. }\end{array}$ \\
\hline $\begin{array}{c}\text { Treatment as Usual (TAU) Tracking } \\
\text { Form }\end{array}$ & Baseline, weekly & $\begin{array}{l}\text { To assess the participant's treatment for substance abuse within } \\
\text { the past week. }\end{array}$ \\
\hline \multicolumn{3}{|c|}{ Measures of Mood, Sleep and Anhedonia } \\
\hline $\begin{array}{l}\text { Quick Inventory of Depressive } \\
\text { Symptomatology- Clinician rated } \\
\left.\text { version (QIDS- } C_{16}\right)\end{array}$ & Baseline, weekly & $\begin{array}{l}\text { To assess severity of depression-specific symptoms. The internal } \\
\text { consistency coefficient is high (Cronbach's alpha of 0.90)[70]. It } \\
\text { also has good concurrent validity, with correlations between the } \\
\text { QIDS and the } 17 \text {-item Hamilton Rating Scale for Depression } \\
\text { ranging between } .86 \text { and } .93 \text {. It also has been shown to have } \\
\text { good inter-rater reliability with a kappa of } .85 \text {. }\end{array}$ \\
\hline $\begin{array}{c}\text { Concise Health Risk Tracking- Self- } \\
\text { report (CHRT-SR) }\end{array}$ & Baseline, weekly & $\begin{array}{l}\text { To assess suicidality and related thoughts and behaviors. The } \\
\text { CHRT-SR has good internal consistency (Cronbach's alpha of } 0.78 \text { ). }\end{array}$ \\
\hline $\begin{array}{l}\text { Concise Associated Symptoms } \\
\text { Tracking- Self-report (CAST-SR) }\end{array}$ & Baseline, weekly & $\begin{array}{l}\text { To assess symptoms related to suicidal thoughts and behaviors. } \\
\text { The internal consistency coefficient for the CAST-SR is good } \\
\text { (Cronbach's alpha of } 0.77) \text {. }\end{array}$ \\
\hline $\begin{array}{l}\text { Snaith-Hamilton Pleasure Scale } \\
\text { (SHAPS) }\end{array}$ & Baseline, monthly & $\begin{array}{l}\text { To measure anhedonia, the inability to experience pleasure. The } \\
\text { SHAPS has adequate construct validity, satisfactory test-retest } \\
\text { reliability [117], and high internal consistency (Cronbach's alpha of } \\
\text { 0.94)[117]. }\end{array}$ \\
\hline \multicolumn{3}{|c|}{ Psychosocial Assessments } \\
\hline Short-Form Health Survey (SF-36) & Baseline, monthly & $\begin{array}{c}\text { To assess quality of life and general health. Internal consistency } \\
\text { reliability coefficients for the SF-36 are high (all greater than } 0.80 \text { ). } \\
\text { Test-retest coefficients range from } 0.43 \text { to } 0.90 \text { for a } 6 \text {-month } \\
\text { interval and from } 0.60 \text { to } 0.81 \text { for a } 2 \text {-week interval. The SF- } 36 \text { has } \\
\text { been shown to correlate moderately well with other health } \\
\text { measures. }\end{array}$ \\
\hline $\begin{array}{l}\text { Quality of Life Enjoyment and } \\
\text { Satisfaction Questionnaire Short } \\
\text { Form (Q-LES-Q-SF) }\end{array}$ & Baseline, monthly & $\begin{array}{l}\text { To evaluate general life enjoyment and satisfaction. Test-retest } \\
\text { reliability for the Q-LES-Q-SF has been shown to be } .86[118] \text { and } \\
\text { internal consistency (Cronbach's alpha) has been shown to range } \\
\text { from } .86 \text { to } .90[118,119] .\end{array}$ \\
\hline $\begin{array}{c}\text { Pain Frequency, Intensity and } \\
\text { Burden Scale (P-FIBS) }\end{array}$ & Baseline, monthly & $\begin{array}{l}\text { To evaluate the frequency, intensity, and burden of pain over the } \\
\text { past week, as well as usage of pain medication to manage pain. }\end{array}$ \\
\hline \multicolumn{3}{|c|}{ Cognitive Function Assessments } \\
\hline $\begin{array}{l}\text { Wechsler Test of Adult Reading } \\
\text { (WTAR) }\end{array}$ & Baseline & $\begin{array}{c}\text { To assess pre-morbid intelligence. The WTAR has been established } \\
\text { to be a reliable and valid assessment of pre-morbid intelligence. It } \\
\text { has been normed with the Wechsler Adult Intelligence Scale } \\
\text { (WAIS-III) and the Wechsler Memory Scale (WMS-III). }\end{array}$ \\
\hline $\begin{array}{l}\text { MGH Cognitive and Physical } \\
\text { Functioning Questionnaire (CPFQ) }\end{array}$ & Baseline, monthly & $\begin{array}{l}\text { To assess physical well-being and cognitive and executive } \\
\text { dysfunction. The CPFQ has been shown to have high internal } \\
\text { consistency with a Cronbach's alpha of } 0.90 \text { and test-retest } \\
\text { reliability }(0.83, p<0.001)[120] \text {. }\end{array}$ \\
\hline Stroop Color and Word Test (Stroop) & Baseline, weeks 13, 37 & To measure attention response inhibition. \\
\hline \multicolumn{3}{|c|}{ Physiological Measures } \\
\hline Physiological Measures & $\begin{array}{l}\text { Baseline, monthly (height once at } \\
\text { baseline, weight weekly) }\end{array}$ & $\begin{array}{l}\text { To measure height, weight, body mass index (BMI), and waist } \\
\text { circumference }\end{array}$ \\
\hline Exercise Readiness Form & $\begin{array}{c}\text { Baseline, each supervised exercise session } \\
\text { (3X/wk for } 1^{\text {st }} 3 \text { months, } 1 \mathrm{X} / \mathrm{wk} \text { for next } 6 \\
\text { months) }\end{array}$ & $\begin{array}{l}\text { To measure resting heart rate and blood pressure for those in the } \\
\text { exercise condition in order to evaluate safety for exercise. }\end{array}$ \\
\hline \multicolumn{3}{|c|}{ Retention } \\
\hline $\begin{array}{l}\text { Treatment Participation } \\
\text { Questionnaire (TPQ) }\end{array}$ & Baseline, weekly & To assess participant's likelihood of remaining in treatment. \\
\hline
\end{tabular}

Pleasure Scale (SHAPS)[71] will be used to measure anhedonia. Suicidality and related symptoms will be evaluated throughout the study using the Concise
Health Risk Tracking - Self-Report (CHRT-SR), and the Concise Associated Symptoms Tracking - Self-Report (CAST-SR). 
Psychosocial assessments will include the Quality of Life Enjoyment and Satisfaction Questionnaire Short Form (Q-LES-Q-SF [72]), the Short-Form Health Survey (SF-36 [73,74]), and the Pain Frequency, Intensity and Burden Scale (P-FIBS). Assessments of cognitive function will include the Stroop Color and Word Test [75,76], a measure of attention response inhibition, and the MGH Cognitive and Physical Functioning Questionnaire (CPFQ [77]), a measure of subjective cognitive function. The Wechsler Test of Adult Reading (WTAR [78]) will be administered at baseline to assess premorbid intelligence.

\section{Fitness and Physiological Measures}

Physiological measures include height, weight, body mass index (BMI), and waist circumference. For those participants in the exercise intervention, resting heart rate and blood pressure will be obtained prior to each exercise session using the Exercise Readiness Form in order to evaluate safety to exercise. Resting heart rate and blood pressure will be obtained for all participants during the maximal exercise test. The maximal exercise will be repeated at week 13 to assess change in fitness.

\section{Retention}

The Treatment Participation Questionnaire (TPQ), a fiveitem self-report that assesses the participant's likelihood of remaining in treatment for substance abuse and continuing to attend study visits, will be administered at baseline and then weekly thereafter. Since this study is designed as an intent-to-treat study, subjects will be encouraged to complete assessments regardless of their status in their treatment programs or their engagement in the study intervention.

\section{Analytic Methods}

The primary analysis will compare the primary outcome between the two treatments taking into account possible variability in the overall level of abstinence between sites. More specifically, we use a mixed normal model with a fixed treatment effect and random terms for site and error. The model considers treatment effect to be the same in each site. P-value less than 0.05 will be considered statistically significant. The assumed treatment effect $\mu_{V I H D}-\mu_{H E C}$ is 0.15 . The error standard deviation $\sigma$ is considered to be in the range between 0.40 and 0.45 , and abstinence status within participant is assumed to be correlated across days. The primary endpoint will be analyzed on an intent-to-treat basis, meaning that participants' data will be analyzed according to the group they were randomized to, regardless of the subsequent sequence of events (e.g., noncompliance to the intervention).

Even though the overall level of outcome may differ across sites (i.e. $\sigma_{\text {site }}>0$ ), the primary analysis removes this variation by adjusting for site in the model. Hence, initial sample size computations are based on value of error standard deviation $\sigma$ and the sample size estimates are based on a two sample t-test formula. A treatment effect that varies across sites may contribute additional variation and simulations with primary analysis performed for each simulation were used to investigate this possibility. Based on these simulations, and as an additional precaution, we increased initial sample size by $10 \%$ to attempt to take into consideration potential treatment effect variability. Based on these considerations, we proposed the trial to enroll 330 participants. Clearly, the proposed sample size depends on accurate estimation of variability $\sigma$. We propose to reassess this variability midway through the study, i.e., after approximately 165 participants have enrolled and completed the acute phase of the trial, and may readjust needed sample size if the variance assumption proves incorrect.

\section{Rationale for Key Study Design Choices Population}

For this study, we chose to specifically evaluate individuals with stimulant abuse or dependence. This decision was made in order to reduce heterogeneity of the sample with respect to drug use, since this is an early efficacy trial with a new intervention in a substance using population.

\section{Setting}

This study is designed to start while participants are in a residential setting and continues as participants transition into outpatient and other community care. Starting treatment in the residential setting was chosen to maximize the availability of participants to be present for the initial evaluation and training of the exercise intervention. Given the dose and intensity of exercise selected for this study, it is critical that participants be consistent in attending supervised sessions, particularly as they are first learning how to implement the exercise protocol, how to use all related equipment, and how to collect and record all exercise-related data. A transition to outpatient care is a typical occurrence in the treatment of substance use disorders. This study is designed to evaluate participants as they transition to the next phase of care. While the decision to begin in a residential setting could result in somewhat less generalizability of findings, since this is an early efficacy study, we determined that it was more important to ensure that our study population was present to receive sufficient training and supervision in the exercise intervention and to maximize adherence during this time.

\section{Study Duration}

The total duration of participation in STRIDE is 9 months. A 6-month duration for the continuation phase was selected because we would like to see if there is a sustained response to the exercise intervention. In most chronic diseases, longer-term outcomes are best seen in the 6 months following acute phase intervention. 


\section{Exercise Intervention}

One of the major hurdles in successfully conducting exercise trials has been the inconsistency of type, dose, and intensity of exercise achieved. We elected to define exercise type, dose and intensity in this study to minimize variability and to achieve pre-specified targets for both dose and intensity.

\section{Type}

We selected the use of aerobic exercise in this trial. While there is some evidence that other types of exercise (e.g., weight training) may be beneficial to individuals with other disorders, such as depression, the preponderance of existing evidence supports the use of aerobic exercise. Furthermore, aerobic exercise has been used in previous interventions involving substance abuse disorders [7-11,18].

\section{Dose}

A $12 \mathrm{KKW}$ dose of exercise was selected for this study for the following reasons: 1) it is consistent with U.S. 2008 Physical Activity Guidelines http://www.health.gov/ paguidelines, as well as prior recommendations from groups such as the Centers for Disease Control and Prevention and ACSM [79-83], the NIH Consensus panel $[45,79,80,82-86]$, and the U.S. Surgeon General (U.S. Department of Health and Human Services [87]); 2) it has been used in previous studies involving physical activity interventions in smokers [7,9], and in other disorders such as depression [54,88-91], it is consistent with doses associated with biological changes that we hypothesize will impact stimulant use such as alterations of the serotonergic [92-94] and endocannabinoid systems [95], attenuated stress responses [96,97], and increases in release of BDNF [98].

\section{Intensity}

An intensity range of 70-85\% of an individual's $\mathrm{HR}_{\max }$ was selected for this study. This intensity is above the suggested minimum intensity of $50 \%$ of $\mathrm{HR}_{\max }$ and within the currently recommended training intensity guidelines for producing physiological adaptations and benefits [51]. Although higher exercise intensities may produce greater changes in outcomes at a constant dose, for this efficacy trial we want to be certain that we are well within standard exercising ranges for both dose and intensity. By selecting a range of $70-85 \%$ of $\mathrm{HR}_{\max }$, we have allowed for some exercising flexibility to increase comfort, while ensuring that all participants are exercising above the minimum recommended threshold.

Alternatively, we could have allowed participants to select their own exercise intensity (i.e., self-selected intensity based on rating of perceived exertion) as long as they achieved the target dose. While this approach would allow significantly greater flexibility for participants, it would likely lead to greater variations in exercise intensity. Another alternative would be to have a fixed exercise intensity (i.e., $80 \% \mathrm{HR}_{\max }$ ) to maximize the standardization of the exercise intervention. However, a fixed intensity would allow little flexibility for participants to find a comfortable exercise level and may, therefore, result in poor adherence and increased drop-outs.

\section{Frequency}

In this study, we recommend that participants complete their prescribed weekly exercise dose over three exercise sessions per week. However, we will allow up to two additional sessions per week in order to accommodate variations in baseline fitness levels. Individuals who are more unfit will have a relatively low caloric expenditure rate when exercising within their relative intensity range (as demonstrated by elevated HRs at low treadmill settings). This will require them to exercise for a greater duration to achieve their weekly exercise dose than individuals who have higher baseline fitness levels. For example, a participant exercising at $70 \%$ of their $\mathrm{HR}_{\max }$ might require $150 \mathrm{~min} /$ week (50 $\mathrm{min} /$ session for three sessions/ week) to achieve the $12 \mathrm{KKW}$ dose, whereas a less fit participant might require $240 \mathrm{~min} /$ week to achieve the same $12 \mathrm{KKW}$ dose due to differences in exercise efficiency and their individual responses to exercise. Therefore, it benefits the second participant to divide their exercise dose among four or five sessions, thereby increasing the feasibility of completing each exercise session and achieving the weekly exercise dose.

\section{Control Group}

A health education intervention attention control group was selected so that the effect of the exercise intervention could not be attributed to the additional contact associated with it. HEI has been established as an ineffective, yet attentionally equivalent control condition in studies of exercise and it has been used successfully $[7,52,53,99,100]$ and with good adherence by members of our study Protocol Development Team (Drs. Marcus, Church, Nunes and Blair). Their use of HEI as a control condition and the knowledge gained from their experience increases the likelihood that participants randomized to this arm of the study will find this intervention acceptable. Participants will be recruited to a "health intervention study", one arm of which is exercise, and the other health education, so that HEI is not described as a control condition. While it is true that participants will know their group assignment, this has not been problematic in other studies using HEI controls and there has not been differential attrition (i.e., Marcus et al. $[7,10])$. Participants in the HEI group will be able to participate in selecting the material that is discussed in order to help maintain interest. Furthermore, they will be monitored similarly to DEI participants, and they will receive the same behavioral intervention strategies as DEI participants in order to maximize adherence. All attempts will be made to address barriers to retention 
in the control condition, as in the exercise intervention. HEI, as opposed to TAU alone, is also intended to ensure continued participant engagement in the study and thus minimize dropouts that might occur if attention in the two groups were not equivalent. Other possible active control conditions (e.g., resistance training, relaxation, yoga, or meditation) have the potential for efficacy, and in fact some have shown efficacy both in substance use and in other disorders (e.g., depression [101]). Thus, the use of an active comparator would make it difficult to see a treatment effect, so these alternative active control conditions are not ideal comparators for an efficacy study of exercise.

\section{Primary Outcome}

The rationale for the outcome for the current study design was driven by the desire to provide a meaningful clinical outcome that would allow for the ready comparison of the effectiveness of this treatment. In addition, it was important that this outcome be suitable for an intent-to-treat study such that all available data could be utilized for analysis. We decided upon an approach that integrates the strengths of multiple measures and allows for data collection over an extended time period [46]. We chose to assess percent days abstinent as measured by self-report using the Timeline Followback. Some studies have shown that this approach has been shown to correlate well with objective measures of use such as urine drug screen [102-104]. Disadvantages of the TLFB include potential inaccuracy due to memory errors and bias and deliberate and denialbased distortions of reported substance use. As a result, two additional tools have been added to the data collection process. The Substance Use Diary, which will aid with recall during the TLFB assessment, has been shown to improve the accuracy of the TLFB [105]. The diary can be completed in real time in between study visits to help participants maintain an accurate accounting of their usage of stimulants, and will be particularly helpful in situations where missed visits occur that result in greater amounts of time to recall. Finally, to further improve the validity of the TLFB, results will be confirmed with urine drug screens collected 3 times per week and an algorithm will be employed at the time of data analysis to reconcile discrepancies between the TLFB and the urine drug screens for the primary outcome.

Choice of the TLFB self-report measure was consistent with several elements of our study design. Our study intervention will be conducted over a 9-month period during which time participants will not only transition from residential to outpatient treatment, but they are expected to come to the study site 3 times a week for the first 12 weeks and once a week for the following 24 weeks. Stimulant abusing patients are known to be inconsistent in their attendance at treatment and study visits [1]. This visit schedule therefore poses a serious challenge to the use of a sole objective measure such as UDS to define abstinent and non-abstinent days and would likely result in considerable missing data. To decrease the potential for missing data due to the short half-life of stimulants, urine drug screens are often obtained 3 times per week, but this frequency of assessment would be very difficult to maintain over a 9month duration. The TLFB, on the other hand, allows for data to be collected on all days, since the interviewer prompts the participant to recall use for all days since the last study visit.

\section{Discussion}

The STRIDE study aims to address the need for novel treatments in stimulant use disorders. Studies demonstrating the effectiveness of exercise in the treatment of nicotine dependence and alcohol abuse suggest that exercise augmentation of treatment as usual may be efficacious in increasing abstinence from stimulant use. The potential effects of exercise on the underlying biological mechanisms of stimulant addiction further support the use of exercise in the treatment of stimulant abuse. Finally, exercise may provide additional health benefits. Stimulant use is detrimental to a number of health domains including sleep [106,107], cognitive function [36], and mood [108], while exercise results in improvement of sleep quality $[26,109]$, cognitive function [110], and mood $[89,94,111,112]$.

Several study design features help accurately assess the efficacy and effectiveness of exercise augmentation for stimulant abuse and dependence. First, the exercise type, dose, and intensity are precisely defined to reduce variability. In addition, this dose of exercise is congruent with current health recommendations and should be sufficient to alter the hypothesized biological underpinnings of stimulant dependence. Second, a comprehensive behavioral intervention program will be implemented to facilitate and monitor adherence to the two interventions. Facilitators will provide participants with adherence feedback and support the participant in addressing barriers to adherence. Finally, the use of a health education intervention control group will provide balanced facilitator attention across the two interventions. Health education groups have proved to be ineffective in previous trials $[7,52,53,99]$, yet demonstrate high levels of adherence and will provide equivalent facilitator contact.

This is one of the first studies conducted within the CTN that is specifically designed as a first test of a new intervention in a specific disorder. As such, it will not only test the efficacy and effectiveness of this intervention for stimulant abuse and dependence, but also provide information about conducting this type of study in the context of a network of community treatment programs. Future studies are needed that evaluate the use 
of exercise in the reduction in use of other illicit substances. In addition, new studies that examine the use of exercise during different phases of treatment are needed. For example, exercise may prove to be effective in reducing symptoms of withdrawal but not in increasing long-term abstinence, or vice versa. Finally, future studies should aim to identify the biological mechanisms responsible for reductions in substance use.

\section{Acknowledgements and funding}

We are particularly grateful to our Protocol Development Team, which guided the STRIDE Study design and includes Steven N. Blair, P.E.D.; Dan G. Blazer, M.D., M.P.H., Ph.D.; Kathleen Brady, M.D., Ph.D.; Timothy Church, M.D., M.P.H., Ph.D.; Tracy L. Greer, Ph.D.; Petra Jacobs, M.D.; Eve Jelstrom, CRNA, M. B.A.; Andrzej Kosinski, Ph.D.; Michael Levy, Ph.D.; Tiffany L. Linkovich Kyle, Ph. D.; David Liu, M.D.; Yuliya Lokhnygina, Ph.D.; Bess H. Marcus, Ph.D.; Edward V. Nunes, M.D.; John P. Rotrosen, M.D.; Jeffrey T. Sharp, M.S.; Eugene Somoza, M.D., Ph.D.; Michele M. Straus, RPh, M.S.; Jose Szapocznik, Ph.D.; Madhukar H. Trivedi, M.D.; Paul Wakim, Ph.D.; and Diane Warden, M.B.A., Ph.D.

We are also greatly appreciative of the RRTC personnel from the Ohio Valley Node and Florida Node of the Clinical Trials Network, who were instrumental in the development of this trial, sharing valuable knowledge and expertise with this team. We also appreciate the expertise and guidance of the STRIDE Executive Committee which includes Colleen Allen, M.P.H., CCRA; Steven N. Blair, P.E.D.; Jack Chally, M.B.A.; Timothy Church, M.D., M.P.H., Ph.D.; Becca Crowell, M.Ed., Ed.S.; Eve Jelstrom, CRNA, M.B.A.; Tracy L. Greer, Ph.D.; Tiffany L. Linkovich Kyle, Ph.D.; David Liu, M.D.; Bess H. Marcus, Ph.D.; Edward V. Nunes, M.D.; Neal Oden Ph.D.; John P. Rotrosen, M.D.; Eugene Somoza, M.D., Ph.D.; James L. Sorensen, Ph.D.; Michele M. Straus, RPh, M.S.; Madhukar H. Trivedi, M.D.; Paul Van Veldhuisen, Ph.D.; Diane Warden, M.B.A. Ph.D.; and Jeremy Wolff, B.A.

We are also very grateful to Barbara Henry for her assistance in preparing the manuscript prior to submission and to Carol A. Tamminga, M.D., Communities Foundation of Texas, Inc. Chair in Brain Science, and Chair, Department of Psychiatry, University of Texas Southwestern Medical Center for administrative support.

This work was supported by the National Institute on Drug Abuse through the Clinical Trials Network for the Texas Node [3U10DA020024-06S1], Madhukar H. Trivedi, M.D., Principal Investigator; and the Stimulant Reduction Intervention using Dosed Exercise (STRIDE) study [2U10DA020024-06], Madhukar H. Trivedi, M.D., Lead Investigator.

\section{Author details}

'The University of Texas Southwestern Medical Center at Dallas, 5323 Harry Hines Blvd., Dallas, Texas, 75390-9119, USA. ${ }^{2}$ Preventive Medicine Laboratory, Pennington Biomedical Research Center, 6400 Perkins Rd, Baton Rouge, LA, 70808, USA. ${ }^{3}$ Cincinnati Addictions Research Center (CinARC); Department of Psychiatry, University of Cincinnati College of Medicine, 260 Stetson St., Cincinnati, OH, 45219, USA. ${ }^{4}$ Department of Exercise Science, University of South Carolina, 514 Main Street, Columbia, SC, 29208 USA. ${ }^{5}$ Department of Epidemiology and Biostatistics, University of South Carolina, 800 Sumter Street, Columbia, SC, 29208, USA. ${ }^{6}$ Department of Epidemiology and Public Health, University of Miami, Miller School of Medicine, 1120 NW $14^{\text {th }}$ Street, Miami, 33136 FL, USA. 'Department of Biostatistics and Bioinformatics, Duke University Medical Center, Duke Clinical Research Institute, P. O. Box 17969, Durham, NC 27715, USA. ${ }^{8}$ The Center for Drug-Free Living, 3670 Maguire Boulevard, Orlando, FL, 32853, USA. ${ }^{9}$ Department of Family and Preventive Medicine, The University of California, San Diego, 9500 Gilman Drive, 0622, La Jolla, California., 92093-0622, USA. ${ }^{10}$ Nexus Recovery Center, Inc., 8733 La Prada Dr. Dallas, Texas, 75228, USA. "'The EMMES Corporation, $401 \mathrm{~N}$. Washington St., Rockville, MD, 20850, USA. ${ }^{12}$ New York State Psychiatric Institute/Department of Psychiatry, College of Physicians and Surgeons of Columbia University, 1051 Riverside Drive, Unit 69, New York, NY 10032, USA.

\section{Authors' contributions}

$M H T$, TLG, and BDG designed the trial, with substantial input from ES, JS, EN, DW, TSC, SNB, TK, BHM, and BC. ASK and NO calculated power and developed plans for statistical analyses. MHT, TLG, BDG, DW, and KMR formalized the procedures for study implementation, with substantial contributions from RW, DWM, ES, and EN on the selection, administration, and training of study assessments. Participant eligibility and recruitment procedures were developed by BDG, TLG, DW, RW, DM, TK, and BC. BDG, $D W, T L G$, and KMR determined site selection criteria with substantial input from TK and BC. CR, MS, TSC, TLG, BHM, MHT, and SNB developed the exercise intervention. KMR, CR, MS, TSC, TLG, BHM, MHT, and SNB developed the health education intervention. BDG, TLG, MHT, CR, DW, SNB, and KMR developed the behavioral adherence program. All authors contributed to revisions of the manuscript prior to submission and read and approved the final manuscript.

\section{Competing interests}

Madhukar H. Trivedi, M.D. is a consultant to or on speaker bureaus for Abbott Laboratories, Inc., Abdi Ibrahim, Akzo (Organon Pharmaceuticals Inc.), AstraZeneca, Bristol-Myers Squibb Company, Cephalon, Inc., Cyberonics Inc., Eli Lilly \& Company, Evotec, Fabre Kramer Pharmaceuticals, Inc., Forest Pharmaceuticals, GlaxoSmithKline, Janssen Pharmaceutica Products, LP, Johnson \& Johnson PRD, Meade Johnson, Medtronic, Neuronetics, Otsuka Pharmaceuticals, Parke-Davis Pharmaceuticals, Inc., Pfizer Inc., Sepracor, SHIRE Development, Solvay Pharmaceuticals, VantagePoint, and Wyeth-Ayerst Laboratories. He receives research support from the Agency for Healthcare Research and Quality (AHRQ), Corcept Therapeutics, Inc., Cyberonics, Inc., Merck, National Alliance for Research in Schizophrenia and Depression, National Institute of Mental Health, National Institute on Drug Abuse, Novartis, Pharmacia \& Upjohn, Predix Pharmaceuticals (Epix), Solvay Pharmaceuticals, Inc., and Targacept.

Tracy L. Greer Ph.D. has received research support from the National Alliance for Research in Schizophrenia and Depression.

Bruce D. Grannemann, M.A. declares that there is no conflict of interest. Timothy S. Church, M.D., Ph.D., M.P.H. declares that there is no conflict of interest.

Eugene Somoza, M.D., Ph.D. declares that there is no conflict of interest. Steven N. Blair, P.E.D. declares that there is no conflict of interest. Jose Szapocznik, Ph.D. declares that there is no conflict of interest. Mark Stoutenberg, Ph.D. declares that there is no conflict of interest. Chad Rethorst, Ph.D. declares that there is no conflict of interest. Diane Warden, Ph.D., M.B.A. has owned stock in Bristol Myers Squibb and Pfizer, Inc. in the last 5 years and has received funding from the National Alliance for Research in Schizophrenia and Depression.

David W. Morris, Ph.D. declares that there is no conflict of interest. Andrzej S. Kosinski, Ph.D. declares that there is no conflict of interest. Tiffany Kyle, Ph.D. declares that there is no conflict of interest. Bess Marcus, Ph.D. declares that there is no conflict of interest. Becca Crowell, M.Ed., Ed.S. declares that there is no conflict of interest. Neal Oden, Ph.D. declares that there is no conflict of interest. Edward Nunes, M.D. has received funding from NIDA for grants K24DA022412 (PI: Nunes) and U10DA13035 (PI: Nunes).

Received: 29 July 2011 Accepted: 19 September 2011

Published: 19 September 2011

\section{References}

1. Dutra L, Stathopoulou G, Basden SL, Leyro TM, Powers MB, Otto MW: A metaanalytic review of psychosocial interventions for substance user disorders. American Journal of Psychiatry 2008, 165:179-187.

2. Ball SA, Martino S, Nich C, Frankforter TL, Van Horn D, Crits-Christoph P, Woody GE, Obert JL, Farentinos C, Carroll KM: Site matters: Multisite randomized trial of motivational enhancement therapy in community drug abuse clinics. Journal of Consulting and Clinical Psychology 2007, 75:556-567.

3. Carroll KM, Ball SA, Nich C: Motivational interviewing to improvement treatment engagement and outcome in individuals seeking treatment for substance abuse: A multisite effectiveness study. Drug and Alcohol Dependence 2006, 80:301-312.

4. Rawson RA, McCann MJ, Flammino F, Shoptaw S, Miotto K, Reiber C, Ling W: A comparison of contingency management and cognitive behavioral approaches for stimulant-dependent individuals. Addiction 2006, 101:267-274

5. Wetzel H, Szegedi A, Scheurich A, Lorch B, Schlafke D, Sittinger $H$, Wobrock T, Muller MJ, Anghelescu I, Hautzinger M, NeVeR Study Group: 
Combination treatment with nefazodone and cognitive-behavioral therapy for relapse prevention in alcohol-dependent men: A randomized controlled study. Journal of Clinical Psychiatry 2004, 65:1406-1413.

6. Vocci FJ, Montoya ID: Psychological treatments for stimulant misuse, comparing and contrasting those for amphetamine dependence and those for cocaine dependence. Current Opinion in Psychiatry 2009, 22(3):263-268.

7. Marcus BH, Albrecht AE, King TK, Parisi AF, Pinto BM, Roberts M: Exercise effects on withdrawal and mood among women attempting smoking cessation. Archives of Internal Medicine 1999, 159:1229-1234.

8. Marcus BH, Albrecht AE, Niaura RS, Abrams DB, Thompson PD: Usefulness of physical exercise for maintaining smoking cessation in women. American Journal of Cardiology 1991, 68:406-407.

9. Marcus BH, Albrecht AE, Niaura RS, Taylor ER, Simkin LF, Feder SI: Exercise enhances the maintenance of smoking cessation in women. Addictive Behaviors 1995, 20:87-95.

10. Marcus BH, Lewis BA, Hogan J, King TK, Albrecht AE, Bock BC, Parisi AF, Niaura RS, Abrams DB: The efficacy of moderate-intensity exercise as an aid for smoking cessation in women: a randomized controlled trial. Nicotine \& Tobacco Research 2005, 7:871-880.

11. Martin JE, Calfas KJ, Patten CA, Polarek M, Hofstetter CR, Noto J, Beach D: Prospective evaluation of three smoking interventions in 205 recovering alcoholics: One-year results of project SCRAP-Tobacco. Journal of Consulting and Clinical Psychology 1997, 65:190-194.

12. Sinyor $D$, Brown $T$, Rostant $L$, Seraganian P: The role of a physical fitness program in the treatment of alcoholism. Journal of Studies on Alcohol 1982, 43:380-386.

13. Collingwood TR, Reynolds R, Kohl HW, Smith W, Sloan S: Physical fitness effects on substance abuse risk factors and use patterns. Journal of Drug Education 1991, 21:73-84

14. Collingwood TR, Sunderlin J, Kohl HW: The use of a staff training model for implementing fitness programming to prevent substance abuse with at-risk youth. American Journal of Health Promotion 1994, 9:20-23, 33.

15. Petry NM, Alessi SM, Marx J, Austin M, Tardiff M: Vouchers versus prizes: Contingency management treatment of substance abusers in community settings. Journal of Consulting and Clinical Psychology 2005, 73:1005-1014.

16. Petry NM, Tedford J, Austin M, Nich C, Carroll KM, Rounsaville BJ: Prize reinforcement contingency management for treatment of cocaine abusers: How low can we go and with whom? Addiction 2004, 99:349-360.

17. Weinstock J, Barry D, Petry NM: Exercise-related activities are associated with positive outcome in contingency management treatment for substance use disorders. Addictive Behaviors 2008, 3(8):1072-1075.

18. Brown RA, Abrantes AM, Read JP, Marcus BH, Jakicic J, Strong DR, Oakley JR, Ramsey SE, Kahler CW, Stuart GG, Dubreuil ME, Gordon AA: A pilot study of aerobic exercise as an adjunctive treatment for drug dependence. Mental Health and Physical Activity 2010, 3:27-34.

19. Frankel A, Murphy J: Physical fitness and personality in alcoholism. Quarterly Journal of Studies on Alcohol 1974, 35:1272-1278.

20. Palmer J, Palmer LK, Michiels K, Thigpen B: Effects of type of exercise on depression in recovering substance abusers. Perceptual and Motor Skills 1995, 80:523-530.

21. Palmer J, Vacc N, Epstein J: Adult inpatient alcoholics: Physical exercise as a treatment intervention. Journal of Studies on Alcohol and Drugs 1988, 49:418-421.

22. Bock BC, Marcus BH, King TK, Borrelli B, Roberts MR: Exercise effects on withdrawal and mood among women attempting smoking cessation Addictive Behaviors 1999, 24:399-410.

23. Kawachi I, Troisi RJ, Rotnitsky AG, Coakley EH, Colditz MD: Can physical activity minimize weight gain in women after smoking cessation? American Journal of Public Health 1996, 86:999-1004.

24. Taylor CB, Sallis JF, Needle R: The relation of physical activity and exercise to mental health. Public Health Reports 1985, 100:195-201.

25. Martin CK, Church TS, Thompson AM, Earnest CP, Blair SN: Exercise dose and quality of life. Archives of Internal Medicine 2009, 169:269-278.

26. Youngstedt SD: Effects of exercise on sleep. Clinical Sports Medicine 2005, 24(2):355-365, xi

27. Borders TF, Booth BM, Falck RS, Leukefeld C, Wang J, Carlson RG: Longitudinal changes in drug use severity and physical health-related quality of life among untreated stimulant users. Addictive Behaviors 2009, 34:959-964.

28. Morgan PT, Pace-Schott EF, Sahul ZH, Coric V, Stickgold R, Malison RT: Sleep, sleep-dependent procedural learning and vigilance in chronic cocaine users: Evidence for occult insomnia. Drug and Alcohol Dependence 2006, 82:238-249.

29. Cowan J, Devine C: Food, eating, and weight concerns of men in recovery from substance addiction. Appetite 2008, 50:33-42.

30. Hodgkins CC, Cahill KS, Seraphine AE, Frost-Pineda K, Gold MS: Adolescent drug addiction treatment and weight gain. Journal of Addictive Disorders 2004, 23:55-66.

31. Hodgkins CC, Jacobs WS, Gold MS: Weight gain after adolescent drug addiction treatment and supervised abstinence. Psychiatric Annals 2003, 33:112-116.

32. Greenwood BN, Strong PV, Foley TE, Fleshner M: A behavioral analysis of the impact of voluntary physical activity on hippocampus-dependent contextual conditioning. Hippocampus 2009, 19:988-1001.

33. Clark PJ, Brzezinska WJ, Thomas MW, Ryzhenko NA, Toshkov SA, Rhodes JS: Intact neurogenesis is required for benefits of exercise on spatial memory but not motor performance or contextual fear conditioning in C57BL/6J mice. Neuroscience 2008, 155:1048-1058.

34. Gomez-Pinilla F, Vaynman S, Ying Z: Brain-derived neurotrophic factor functions as a metabotrophin to mediate the effects of exercise on cognition. European Journal of Neuroscience 2008, 28:2278-2287.

35. Wojtowicz JM, Askew ML, Winocur G: The effects of running and of inhibiting adult neurogenesis on learning and memory in rats. European Journal of Neuroscience 2008, 27:1494-1502.

36. Bolla Kl, Rothman R, Cadet JL: Dose-related neurobehavioral effects of chronic cocaine use. Journal of Neuropsychiatry and Clinical Neurosciences 1999, 11:361-369.

37. Meeusen R: Exercise and the brain: insight in new therapeutic modalities. Annals of Transplantation 2005, 10:49-51.

38. Crews DJ, Landers DM: A meta-analytic review of aerobic fitness and reactivity to psychosocial stressors. Medicine \& Science in Sports \& Exercise 1987, 19 (5 suppl):S114-120

39. Rejeski WJ, Gregg E, Thompson A, Berry M: The effects of varying doses of acute aerobic exercise on psychophysiological stress responses in highly trained cyclists. Journal of Sport \& Exercise Psychology 1991, 13:188-199.

40. McAuley E, Courneya KS, Lettunich J: Effects of acute and long-term exercise on self-efficacy responses in sedentary, middle-aged males and females. The Gerontologist 1991, 31:534-542.

41. Williams PA, Cash TF: A controlled study of the effects of circuit weight training on body image. Paper presented at the Annual meeting of the Association for the Advancement of Behavior Therapy, Toronto, Ontario. 1999.

42. Breus MJ, O'Connor PJ: Exercise induced anxiolysis: a test of the "time out" hypothesis in high-anxious females. Medicine \& Science in Sports \& Exercise 1998, 30:1107-1112.

43. Ussher M, Sampuran AK, Doshi R, West R, Drummond DC: Acute effect of a brief bout of exercise on alcohol urges. Addiction 2004, 99:1542-1547.

44. Marlatt GA, Gordon JR: Relapse prevention: Maintenance strategies in the treatment of addictive behaviors. New York: Guilford Press; 1985

45. Smith E, Meyers RJ, eds: The community reinforcement approach. New York: Guilford Press; 1995

46. Trivedi MH, Greer TL, Potter JS, Grannemann BD, Nunes EV, Rethorst CD, Warden D, Ring KM, Somoza E: Determining the primary endpoint for a stimulant abuse trial: Lessons learned from STRIDE (CTN 0037). The American Journal of Drug and Alcohol Abuse 2011, 37:339-349.

47. Warden $\mathrm{D}$, Trivedi $\mathrm{MH}$, Greer TL, Nunes EV, Grannemann BD, Horigian VE, Somoza E, Ring KM, Kyle T, Szapocznik J: Rationale and methods for site selection for a trial using a novel intervention to treat stimulant abuse. Contemporary Clinical Trials

48. Sobell LC, Sobell MB, eds: Timeline follow-back: A technique for assessing self-reported alcohol consumption. Totowa: Humana Press; 1992.

49. Sobell LC, Sobell MB: Timeline Followback user's guide: A calendar method for assessing alcohol and drug use. Toronto: Addiction Research Foundation; 1996.

50. Oden NL, VanVeldhuisen PC, Wakim PG, Trivedi MH, Somoza E, Lewis D: Power of automated algorithms for combining Time-Line Follow-Back and urine drug screening test results in stimulant-abuse clinical trials. American Journal of Drug and Alcohol Abuse 2011, 37:350-357. 
51. ACSM's Guidelines for Exercise Testing and Prescription. Lippincott Williams \& WIlkins; 82010

52. Rejeski WJ, Fielding RA, Blair SN, Guralnik JM, Gill TM, Hadley EC, King AC, Kritchevsky SB, Miller ME, Newman AB, Pahor M: The lifestyle interventions and independence for elders (LIFE) pilot study: Design and methods. Contemporary Clinical Trials 2005, 26:141-154

53. LIFE Study Investigators, Pahor M, Blair SN, Espeland M, Fielding R, Gill TM, Guralnik JM, Hadley EC, King AC, Kritchevsky SB, Maraldi C, Miller ME, Newman AB, Rejeski WJ, Romashkan S, Studenski S: Effects of a physical activity intervention on measures of physical performance: Results of the lifestyle interventions and independence for Elders Pilot (LIFE-P) study. The Journals of Gerontology, Biological Sciences and Medical Sciences: Series A 2006, 61:1157-1165.

54. Trivedi MH, Greer TL, Grannemann BD, Church TS, Galper DI, Sunderajan P, Wisniewski SR, Chambliss HO, Jordan AN, Finley C, Carmody TJ: TREAD: Treatment with exercise augmentation for depression: Study rationale and design. Clinical Trials 2006, 3:291-305.

55. Robins LN, Wing J, Wittchen HU, Helzer JE, Babor TF, Burke J, Farmer A, Jablensky A, Pickens R, Regier DA, Sartorius N, Towle LH: The Composite International Diagnostic Interview: An epidemiologic instrument suitable for use in conjunction with different diagnostic systems and in different cultures. Archives of General Psychiatry 1988, 45:1069-1077.

56. WHO: Composite International Diagnostic Interview, version 2.1. Geneva: World Health Organization; 1997.

57. Sheehan DV, Lecrubier Y, Harnett-Sheehan K, Janavs J, Weiller E, Keskiner A, Schinka J, Knapp E, Sheehan MF, Dunbar GC: Reliability and validity of the MINI International Neuropsychiatric Interview (M.I.N.I.): According to the SCID-P. European Psychiatry 1997, 12:232-241.

58. Sangha O, Stucki G, Liang MH, Fossel AH, Katz JN: The Self-Administered Comorbidity Questionnaire: A new method to assess comorbidity for clinical and health services research. Arthritis \& Rheumatism 2003, 49:156-163.

59. Canadian Society for Exercise Physiology (CSEP): Physical Activity Readiness Questionnaire (PAR-Q). 2002 [http://www.csep.ca/forms.asp].

60. McLellan AT, Luborsky L, Woody GE, O'Brien CP: An improved diagnostic evaluation instrument for substance abuse patients. The Addiction Severity Index. Journal of Nervous and Mental Disease 1980, 168:26-33.

61. Sussner BD, Smelson DA, Rodrigues S, Kline A, Losonczy M, Ziedonis D: The validity and reliability of a brief measure of cocaine craving. Drug and Alcohol Dependence 2006, 83:233-237.

62. Tiffany ST, Carter BL: Is craving the source of compulsive drug use? Journal of Psychopharmacology 1998, 12:23-30.

63. Kampman KM, Volpicelli JR, McGinnis DE, Alterman Al, Weinrieb RM, D'Angelo L, Epperson LE: Reliability and validity of the Cocaine Selective Severity Assessment. Addictive Behaviors 1998, 23:449-461.

64. Heatherton TF, Kozlowski LT, Frecker RC, Fagerstrom K: The Fagerstrom test for nicotine dependence: a revision of the Fagerstrom tolerance questionnaire. British Journal of Addiction 1999, 86:1119-1127.

65. Kozlowski LT, Porter CQ, Orleans CT, Pope MA, Heatherton T: Predicting smoking cessation with self-reported measures of nicotine dependence: FTQ, FTND, and HIS. Drug and Alcohol Dependence 1994, 34:211-216.

66. Rush AJ, Bernstein IH, Trivedi MH, Carmody TJ, Wisniewski S, Mundt JC, Shores-Wilson K, Biggs MM, Woo A, Nierenberg AA, Fava M: An evaluation of the quick inventory of depressive symptomatology and the Hamilton rating scale for depression: A sequenced treatment alternatives to relieve depression trial report. Biological Psychiatry 2006, 59:493-501.

67. Rush AJ, Carmody TJ, Ibrahim HM, Trivedi MH, Biggs MM, Shores-Wilson K, Crismon ML, Toprac MG, Kashner TM: Comparison of self-report and clinician ratings on two inventories of depressive symptomatology. Psychiatric Services 2008, 57:829-837.

68. Rush AJ, Carmody TJ, Reimitz PE: The Inventory of Depressive Symptomatology (IDS): Clinician (IDS-C) and Self-Report (SR) rating of depressive symptoms. International Journal of Methods in Psychiatric Research 2000, 9:45-59.

69. Rush AJ, Trivedi MH, Ibrahim HM, Carmody TJ, Arnow B, Klein DN, Markogitz JC, Ninan PT, Kornstein S, Manber R, Thase ME, Kocsis JH, Keller MB: The 16-Item Quick Inventory of Depressive Symptomatology (QIDS), clinician rating (QIDS-C), and self-report (QIDS-SR): a psychometric evaluation in patients with chronic major depression. Biological Psychiatry 2003, 54:573-583.

70. Trivedi MH, Rush AJ, Ibrahim HM, Carmody TJ, Biggs MM, Suppes T, Crismon ML, Shores-Wilson K, Toprac MG, Dennehy EB, Witte B, Kashner TM:
The Inventory of Depressive Symptomatology, Clinician Rating (IDS-C) and Self-Report (IDS-SR), and the Quick Inventory of Depressive Symptomatology, Clinician Rating (QIDS-C) and Self-Report (QIDS-SR) in public sector patients with mood disorders, a psychometric evaluation. Psychological Medicine 2004, 34:73-82.

71. Snaith RP, Hamilton M, Humayan A, Hargreaves D, Trigwell P: A scale for the assessment of hedonic tone: The Snaith-Hamilton Pleasure Scale. British Journal of Psychiatry 1995, 167:99-103.

72. Endicott J, Nee J, Harrison W, Blumenthal R: Quality of Life Enjoyment and Satisfaction Questionnaire: a new measure. Psychopharmacology Bulletin 1993, 29:321-326.

73. Ware JE: Conceptualization and measurement of health-related quality of life: comments on an evolving field. Archives of Physical Medicine and Rehabilitation 2003, 84(4 Suppl 2):S43-51.

74. Ware JE, Snow KK, Kosinski M, Gandek B: SF-36 Health Survey Manual and Interpretation Guide. Boston: New England Medical Center, The Health Institute; 1993.

75. Golden CJ: Stroop Color and Word Test: A manual for clinical and experimental uses. Wood Dale: Stoelting Co; 1978.

76. Stroop JR: Studies of interference in serial verbal reactions. Journal of Experimental Psychology 1935, 18:643-662.

77. Fava M, Graves LM, Benazzi F, Scalia MJ, losifescu DV, Alpert JE, Papakostas Gl: A cross-sectional study of the prevalence of cognitive and physical symptoms during long-term antidepressant treatment. Journal of Clinical Psychiatry 2006, 67:1754-1759.

78. Wechsler D: Wechsler test of adult reading. San Antonio: Psychologica Corporation; 2001

79. Haskell WL, Lee IM, Pate RR, Powell KE, Blair SN, Franklin BA, Macera CA, Heath GW, Thompson PD, Bauman A: American College of Sports Medicine; American Heart Association. Physical activity and public health: Updated recommendation for adults from the American College of Sports Medicine and the American Heart Association. Circulation 2007, 116:1081-1093.

80. Haskell WL, Lee IM, Pate RR, Powell KE, Blair SN, Franklin BA, Macera CA, Heath GW, Thompson PD, Bauman A: Physical activity and public health: Updated recommendation for adults from the American College of Sports Medicine and the American Heart Association. Medicine \& Science in Sports \& Exercise 2007, 39:1423-1434.

81. Pate RR, Pratt M, Blair SN, Haskell WL, Macera CA, Bouchard C, Buchner D, Ettinger W, Heath GW, King AC: Physical activity and public health. A recommendation from the Centers for Disease Control and Prevention and the American College of Sports Medicine. Journal of the American Medical Association 1995, 273:402-407.

82. Nelson ME, Rejeski WJ, Blair SN, Duncan PW, Judge JO, King AC, Macera CA, Castaneda-Sceppa C: American College of Sports Medicine; American Heart Association. Physical activity and public health in older adults: Recommendation from the American College of Sports Medicine and the American Heart Association. Circulation 2007, 116:1094-1105.

83. Nelson ME, Rejeski WJ, Blair SN, Duncan PW, Judge JO, King AC, Macera CA, Castaneda-Sceppa C: Physical activity and public health in older adults: recommendation from the American College of Sports Medicine and the American Heart Association. Medicine \& Science in Sports \& Exercise 2007, 39:1435-1445.

84. NIH Consensus Development Panel on Physical Activity and Cardiovascular Health: Physical activity and cardiovascular health. Journal of the American Medical Association 1996, 276:241-246.

85. Fletcher GF, Balady G, Froelicher VF, Harley LH, Haskell WL, Pollock ML: Exercise standards. A statement for healthcare professionals from the American Heart Association. Writing Group. Circulation 1995, 91:580-615.

86. Smith SC, Blair SN, Criqui MH, Fletcher GF, Fuster V, Gersh BJ, Gotto AM, Gould KL, Greenland P, Grundy SM: AHA consensus panel statement. Preventing heart attack and death in patients with coronary disease. The Secondary Prevention Panel. Journal of the American College of Cardiology 1995, 26:292-294.

87. US Department of Health and Human Services (USDHHS): Physical activity and health: A report of the Surgeon General. US Department of Health and Human Services, Centers for Disease Control and Prevention, National Center for Chronic Disease Prevention and Health Promotion 1996 [http:// www.cdc.gov/nccdphp/sgr/contents.htm].

88. Blumenthal JA, Babyak MA, Doraiswamy PM, Watkins L, Hoffman BM, Barbour KA, Herman S, Craighead WE, Brosse AL, Waugh R, Hinderliter A, 
Sherwood A: Exercise and pharmacotherapy in the treatment of major depressive disorder. Psychosomatic Medicine 2007, 69:587-596.

89. Dunn AL, Trivedi MH, Kampert JB, Clark CG, Chambliss HO: Exercise treatment for depression: Efficacy and dose response. American Journal of Preventive Medicine 2005, 28:1-8.

90. Veale D, Le Fevre K, Pantelis C, de Souza V, Mann A, Sargeant A: Aerobic exercise in the adjunctive treatment of depression: $\mathrm{A}$ randomized controlled trial. Journal of the Royal Society of Medicine 1992, 85:541-544.

91. Trivedi MH, Greer TL, Grannemann BD, Chambliss HO, Jordan AN: Exercise as an augmentation strategy for treatment of major depression. Journal of Psychiatric Practice 2006, 12:205-213.

92. Chaouloff F: Effects of acute physical exercise on central serotonergic systems. Medicine \& Science in Sports \& Exercise 1997, 29:58-62.

93. Weicker $H$, Struder HK: Influence of exercise on serotonergic neuromodulation in the brain. Journal of Amino Acids 2001, 20:35-47.

94. Wipfli B, Landers D, Nagoshi C, Ringenbach S: An examination of serotonin and psychological variables in the relationship between exercise and mental health. Scandinavian Journal of Medicine \& Science in Sports 2011, 21:474-481.

95. Sparling PB, Giuffrida A, Pilmelli D, Rosskopf L, Dietrich A: Exercise activates the endocannabinoid system. NeuroReport 2003, 14(17):2209-2211.

96. Blumenthal JA, Emery CF, Walsh MA, Cox DR, Kuhn CM, Williams RB, WIlliams RS: Exercise training in healthy Type A middle-aged men: Effects on behavioral and cardiovascular responses. Psychosomatic Medicine 1988, 50(4):418.

97. Blumenthal JA, Fredrikson M, Kuhn CM, Ulmer RL, Walsh-Riddle M, Appelbaum M: Aerobic exercise reduces levels of cardiovascular and sympathoadrenal responses to mental stress in subjects without prior evidence of myocardial isochemia. American Journal of Cardiology 1990, 65(1):93-98.

98. Seifert T, Brassard P, Wissenberg M, Rasmussen P, Nordby P, Stallknecht B, Adser $H$, Jakobsen AH, Pilegaard H, Nielsen HB, Secher NH: Endurance training enhances BDNF release from the human brain. American Journal of Physiology - Regulatory, Integrative and Comparative Physiology 2010, 298(2):R372.

99. Smolander J, Blair SN, Kohl HW: Work ability, physical activity, and cardiorespiratory fitness: 2-year results from Project Active. Journal of Occupational and Environmental Medicine 2000, 42:906-910.

100. Hien DA, Wells EA, Jiang H, Suarez-Morales L, Campbell AN, Cohen LR, Miele GM, Killeen T, Brigham GS, Zhang Y, Hansen C, Hodgkins C, HatchMaillette M, Brown C, Kulaga A, Kristman-Valente A, Chu M, Sage R, Robinson JA, Liu D, Nunes EV: Multisite randomized trial of behavioral interventions for women with co-occurring PTSD and substance use disorders. Journal of Consulting and Clinical Psychology 2009, 77:607-619.

101. Pilkington K, Kirkwood G, Rampes H, Richardson J: Yoga for depression: The research evidence. Journal of Addictive Disorders 2005, 89:13-24.

102. Nunes EV, McGrath PJ, Quitkin FM, Ocepek-Welikson K, Stewart JW, Koenig T, Wager S, Klein DF: Imipramine treatment of cocaine abuse: Possible boundaries of efficacy. Drug and Alcohol Dependence 1995, 39:185-195.

103. Nunes EV, Quitkin FM, Donovan SJ, Deliyannides D, Ocepek-Welikson K, Koenig T, Brady R, McGrath PJ, Woody GE: Imipramine treatment of opiate-dependent patients with depressive disorders. A placebocontrolled trial. Archives of General Psychiatry 1998, 55:153-160.

104. Magura S, Kang SY: Validity of self-reported drug use in high risk populations: a metaanalytical review. Substance Use and Misuse 1996, 31:1131-1153.

105. Hersh D, Mulgrew CL, Van Kirk J, Kranzler HR: The validity of self-reported cocaine use in two groups of cocaine abusers. Journal of Consulting and Clinical Psychology 1999, 67:37-42

106. Morgan PT, Malison RT: Cocaine and sleep: early abstinence. ThescientificWorldJournal 2007, 7:223-230.

107. Valladares EM, Irwin MR: Polysomnographic sleep dysregulation in cocaine dependence. TheScientificWorldJournal 2007, 7:213-216.

108. Rounsaville BJ, Anton SF, Carroll KM, Budde D, Prusoff BA, Gawin F: Psychiatric diagnoses of treatment-seeking cocaine abusers. Archives of General Psychiatry 1991, 48(1):43-51.

109. Kubitz K, Landers D, Petruzzello S, Han M: The effects of acute and chronic exercise on sleep. A meta-analytic review. Sports Medicine 1996, 21(4):277-291.
110. Hillman C, Erickson K, Kramer A: Be smart, exercise your heart: exercise effects on brain and cognition. Nature Reviews Neuroscience 2008, 9(1):58-65.

111. Rethorst CD, Wipfli BM, Landers DM: The antidepressive effects of exercise. Sports Medicine 2009, 39(6):491-511.

112. Wipfli BM, Rethorst CD, Landers DM: The anxiolytic effects of exercise: a meta-analysis of randomized trials and dose-response analysis. Journal of Sport \& Exercise Psychology 2008, 30(4):392-410.

113. Sheehan DV, Lecrubier Y, Sheehan KH, Amorim P, Janavs J, Weiller E, Hergueta T, Baker R, Dunbar GC: The Mini-International Neuropsychiatric Interview (M.I.N.I.): The development and validation of a structured diagnostic psychiatric interview for DSM-IV and ICD-10. Journal of Clinical Psychiatry 1998, 59(Suppl 20):22-33, quiz 34-57.

114. Fals-Stewart W, O'Farrell TJ, Freitas TT, McFarlin SK, Rutigliano P: The timeline followback reports of psychoactive substance use by drugabusing patients: psychometric properties. Journal of Consulting and Clinical Psychology 2000, 68:134-144.

115. Paliwal P, Hyman SM, Sinha R: Craving predicts time to cocaine relapse: Further validation of the now and brief versions of the cocaine craving questionnaire. Drug and Alcohol Dependence 2008, 93:252-259.

116. Cacciola JS, Alterman Al, McLellan AT: Initial evidence for the reliability and validity of a "Lite" version of the Addiction Severity Index. Drug and Alcohol Dependence 2007, 87:297-302.

117. Franken IHA, Rassin $E$, Muris $P$ : The assessment of ahedonia in clinical and non-clinical populations: Further validation of the Snaith-Hamilton pleasure scale (SHAPS). Journal of Affective Disorders 2007, 99:83-89.

118. Wyrwich K, Harnam N, Revicki DA, Locklear JC, Svedsater H, Endicott J: Assessing health-related quality of life in generalized anxiety disorder using the Quality of Life Enjoyment and Satisfaction Questionnaire. International Clinical Psychopharmacology 2009, 24:289-295.

119. Rapaport MH, Clary C, Fayyad R, Endicott J: Quality-of-life impairment in depressive and anxiety disorders. American Journal of Psychiatry 2005, 62:1171-1178.

120. Fava M, losifescu DV, Pedrelli P, Baer L: Reliability and validity of the Massachusetts general hospital cognitive and physical functioning questionnaire. Psychotherapy and Psychosomatics 2009, 78:91-97.

\section{doi:10.1186/1745-6215-12-206}

Cite this article as: Trivedi et al: Stimulant Reduction Intervention using Dosed Exercise (STRIDE) - CTN 0037: Study protocol for a randomized controlled trial. Trials 2011 12:206.

\section{Submit your next manuscript to BioMed Central and take full advantage of:}

- Convenient online submission

- Thorough peer review

- No space constraints or color figure charges

- Immediate publication on acceptance

- Inclusion in PubMed, CAS, Scopus and Google Scholar

- Research which is freely available for redistribution

Submit your manuscript at www biomedcentral com/submit
Biomed Central 